\title{
Martin Werneyer • Bernd Kramer \\ Electric signalling and reproductive behaviour in a mormyrid fish, the bulldog Marcusenius macrolepidotus (South African form)
}

\author{
Received: June 3, 2004 / Accepted: October 28, 2004 / Published online: April 13, 2005
}

\begin{abstract}
Bulldog fish (Marcusenius macrolepidotus) generate short ( $<1 \mathrm{~ms})$ electric-organ discharges (EODs), separated by much longer and highly variable interdischarge intervals (IDIs). We observed overt behaviour and electrical activity during reproductive behaviour in a male and in a female bulldog, and identified IDI patterns with putative signal functions. In contrast to Pollimyrus adspersus and Pollimyrus isidori, in which an elaborate and extended courtship precedes spawning proper, our fish started spawning almost immediately when we allowed the female to enter the male's territory. The male did not construct a nest, and neither parent provided parental care. The male showed very little aggression towards the intruding female. Fish spawned in bouts near the male's hiding place, and eggs were scattered by the female's vigorous tail flips as she left the spawning site, only to return shortly thereafter. During spawning bouts, both fish generated highly stereotyped IDI patterns: the male generated a series of IDIs gradually decreasing from about $200 \mathrm{~ms}$ to about $55 \mathrm{~ms}$ that was abruptly terminated by a long IDI. The female generated a series of relatively regular IDIs (about $54 \mathrm{~ms}$ ) that was followed by a marked increase in IDI duration (the probable time of spawning). Finally, a sharp decrease in IDIs to about $20 \mathrm{~ms}$ accompanied the female's sudden escape from the spawning site. In between spawning bouts, both fish generated series of very short IDIs (high discharge rate, HD) that alternated abruptly with very low-rate inter-HD activity (especially in the male). IDIs as short as $9 \mathrm{~ms}$ (male) or $11 \mathrm{~ms}$ (female) occurred during HD displays. No visible aggression, in fact very little overt behaviour, occurred during these HD displays in both fish. Agonistic interactions between male and female, outside a reproductive context, were similar to those previously described in male pairs, including overt behavioural patterns such as parallel swim-
\end{abstract}

M. Werneyer · B. Kramer $(\bowtie)$

Zoologisches Institut der Universität Regensburg, 93040 Regensburg, Germany

Tel. +49-941-9432263; Fax +49-941-9432905

e-mail: Bernd.Kramer@biologie.uni-regensburg.de ming, antiparallel display and attack, as well as HD displays. When not interacting, fish did not generate HD displays. We suggest the HD display is a communication signal in both reproductive and agonistic contexts.

Key words Reproduction · Spawning - Mormyrids · Electrocommunication · Agonistic

\section{Introduction}

Electric fish from the family Mormyridae generate short (in many species $<1 \mathrm{~ms}$, as was the case here) electric-organ discharges (EODs), separated by much longer (about 101,000 ms) interdischarge intervals (IDIs) (reviews Kramer 1990a, 1996; Moller 1995). The EOD waveform of an individual fish is usually constant over long periods of time (e.g., Kramer and Westby 1985), and EOD waveforms are species-specific for a community (Kramer 1996; Hopkins 1999). The IDI is highly variable both within and between species. Specific IDI patterns are correlated with certain overt behavioural patterns (Bauer 1972; Bell et al. 1974; Kramer 1974, 1976; Kramer and Bauer 1976; Scheffel and Kramer 1997; Werneyer and Kramer 2002). Möhres (1957), Lissmann (1958) and Szabo (in Lissmann 1961) suggested a communication function of EOD and IDI pattern, which was confirmed much later when electrocommunication was studied mainly in Gnathonemus petersii (e.g., Bauer 1973; Bell et al. 1974; Kramer 1974), and in Pollimyrus adspersus (Bratton and Kramer 1989). The signal function of certain IDI patterns was demonstrated in playback experiments by Kramer (1979).

Despite the high species diversity (mormyrids represent the largest family of freshwater fish endemic to Africa, about 200 species), electrocommunication has been studied in a few species only. Even with the most recent data-acquisition and analysis equipment, the study of electrocommunication remains difficult, especially in unrestricted, freely moving fish allowed to display their full repertoire of behavioural patterns. 
Few species have been successfully bred in captivity, and electrocommunication during reproductive behaviour has been studied in detail only in $P$. adspersus (Bratton and Kramer 1989, then correctly termed $P$. isidori). A better knowledge of electrocommunication in reproductive context is required for an understanding of behaviour and evolution in electric fish.

Our study describes the overt behaviour and the concurrent IDI patterns in the bulldog (Marcusenius macrolepidotus, South African form). This species has been successfully bred in our laboratory, and we identified IDI patterns with putative signal functions during reproductive behaviours.

\section{Materials and methods}

We observed courtship and reproduction in one male and one female bulldog. They originated from a group of $M$. macrolepidotus that were caught in 1997 in the Crocodile River, Mpumalanga Province, South Africa, and immediately exported to Germany where we kept them in our aquaria (for further information, see Werneyer and Kramer 2002). In December 1999 and March 2001, standard lengths (SL) were 15.5 and $16 \mathrm{~cm}$ for the female, and 21.6 and $21.7 \mathrm{~cm}$ for the male (as determined from photographs). Both fish were well beyond $40 \%$ of the maximum species size $(30 \mathrm{~cm}$, Skelton 2001) which is the minimum size for sexual maturity (Kramer 1997).

Prior to observations we kept the female together with two other females in individual compartments of an aquarium that was subdivided by two solid plastic partitions, and the male in another aquarium. Water temperature was $20 \pm 0.5^{\circ} \mathrm{C}$ in both aquaria, water conductivity was $100 \pm 5 \mu \mathrm{S} / \mathrm{cm}$. We exchanged up to one-half of the aquarium water with fresh water of $90-91 \mu \mathrm{S} / \mathrm{cm}$ per week. L:D cycle was $12: 12 \mathrm{~h}$. We fed the fish with frozen or live Chironomus larvae, sometimes with a small earthworm.

Because we found a few eggs in the female's compartment (even though no male was present), we transferred the male and the female into an aquarium of their own $(240 \times 50 \times 60 \mathrm{~cm}$ high; the numbering of days refers to the day of transfer as day 0). A plastic mesh partition divided the aquarium into two equal-sized compartments, one for each fish. The partition was left in place to protect the female from male aggression, but for some observations we removed it for 30-120 min. Both compartments contained porous pots, flower pots, flat stones and driftwood to offer the fish a variety of hiding places. To imitate the beginning of the hot season we raised the water temperature to $22 \pm 0.5^{\circ} \mathrm{C}$ on day 5 .

During behavioural observations, EODs were recorded simultaneously from four pairs of carbon electrodes fixed on the aquarium walls (for details of arrangement, see Werneyer and Kramer 2002). The potential difference was separately amplified (GVJ, GV3, Elektronische Werkstätten der Universität Regensburg) and separately recorded on four channels of an eight-channel instrumentation tape recorder (Racal StorePlus, Racal Recorders). Overt behaviour was videotaped with the experimenter hidden behind a curtain. At night we used infrared illumination. A time reference signal was stored on both video and instrumentation tapes to facilitate off-line synchronisation. An electronic "pulse marker", triggered by EODs as well as by the time reference signal, generated a synchronisation signal on the video image for precise synchronisation of EOD recordings with the sequence of video images.

Selected video sequences were digitized (video card for PC, AV Master, Fast Multimedia AG) and stored on hard disk. Corresponding EOD recordings and time reference signals were replayed from the instrumentation tape recorder and continuously digitized by a computerised A/D system (Hydra, Kinzinger Systeme; simultaneous digitization of up to eight channels) at a sampling rate of $50 \mathrm{kHz}$ at 12 bit vertical resolution.

For data processing and display on PC screen, we programmed routines using Diadem 8.1 (National Instruments). (1) EODs were automatically located using an amplitude trigger criterion and stored, centred in a 1-ms window per EOD (50 samples per channel). Then EODs were automatically assigned to the male or the female by estimating EOD duration (the male's EODs were of longer duration than the female's). For a reliable automatic estimation of EOD duration it was necessary to eliminate the great fluctuations in EOD amplitude and polarity reversals caused by fish movements. (2) Therefore, each single EOD was normalised in amplitude automatically, involving inversion to head-positive polarity on each single channel (if necessary), summation of all channels, and, finally, normalising to a positive peak amplitude of $1 \mathrm{~V}$. This procedure combined all four recording channels to form a single, normalised EOD waveform (50 samples $=1 \mathrm{~ms}$; peak amplitude, $1 \mathrm{~V}$; see Fig. 1). (3) EOD duration was estimated automatically by counting the number of samples above $+0.15 \mathrm{~V}$ or below $-0.15 \mathrm{~V}$ in the normalised waveform (typically $>30$ of the 50 samples in the male, $<30$ in the female), and was used for automatic EOD assignment. (4) Finally, the crossing of the zero line between the positive and the negative peak of the EOD was identified automatically as the time of EOD occurrence used for IDI calculation. The software allowed the simultaneous display of all four recording channels on the PC screen. We used this option in cases of difficulty (for example, when temporally overlapping EODs had to be interpreted and assigned manually). This procedure yielded sequences of IDIs that were concurrent with the videotaped overt behaviour of each fish.

Single EODs for waveform analysis were recorded at high resolution during the day when the fish were resting. We placed one carbon electrode each in front of the head and behind the tail of a fish. A differential amplifier (GVI, Elektronische Werkstätten der Universität Regensburg, variable gain $2-100 \times, 1 \mathrm{~Hz}-100 \mathrm{kHz}$ ) was connected to an oscilloscope (TDS 420, Tektronix, sampling rate adjusted to $500 \mathrm{kHz}, 11$-bit vertical resolution, 2,500-15,000 points per trace). Single-sweep traces were transferred to computer and normalised to a positive peak of $1 \mathrm{~V}$ (using the signal 
Fig. 1. Bottom Section of a recording from a pair of freeswimming bulldogs, shown for two of the four recording channels (50-kHz digitization). On the basis of electric-organ discharge (EOD) duration the left EOD was assigned to the female, the right one to the male. Note the clear difference in EOD duration in normalised EOD waveforms (top panels) even though the male EOD was recorded at weak amplitude on both channels, and the female EOD clipped by amplifier saturation

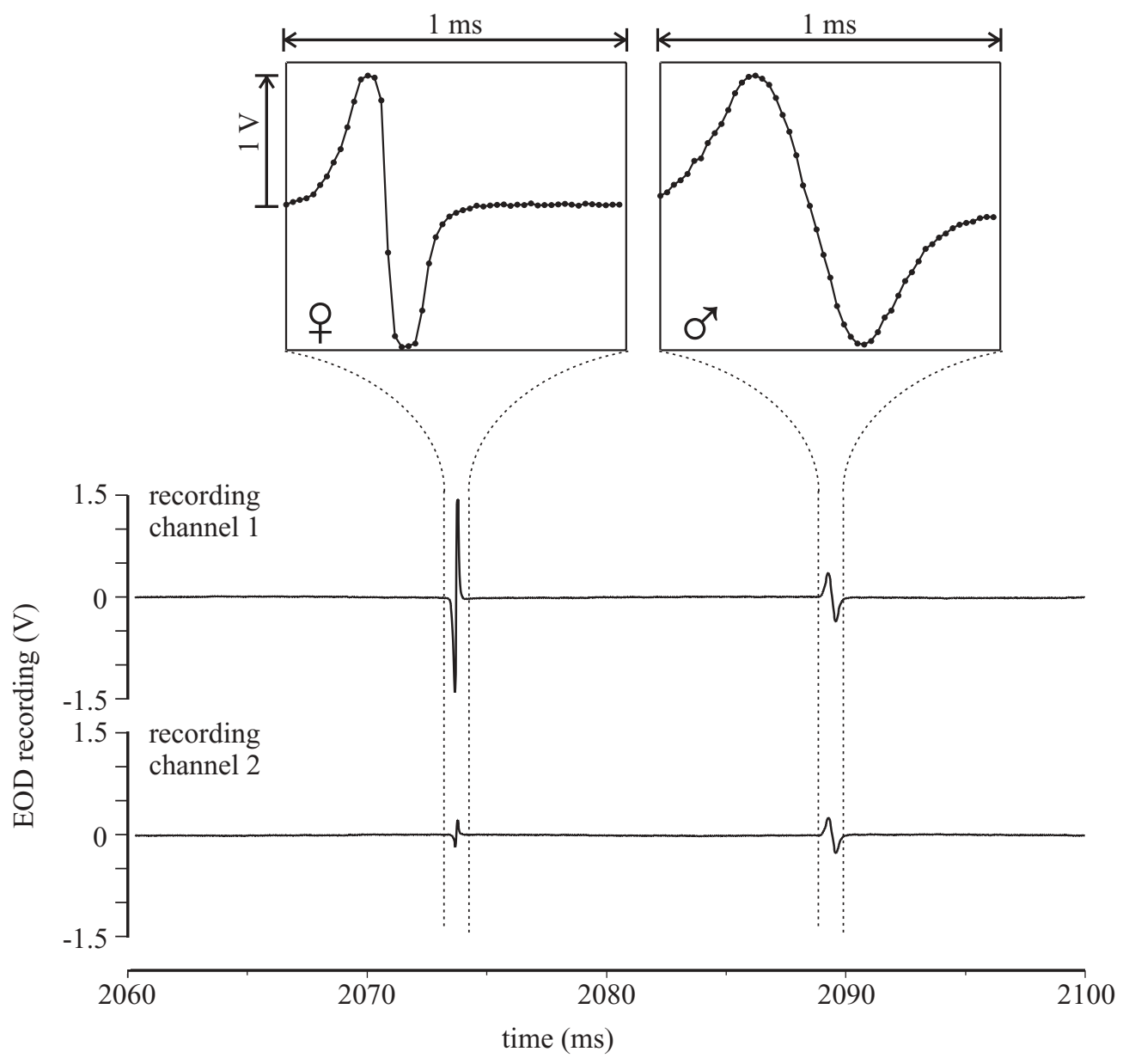

analysis package FAMOS 4.0, IMC). To reduce noise, we averaged four normalised EODs per fish per session. Because of the asymptotic start and termination of an EOD we used a $\pm 5 \%$ criterion of the positive EOD peak for determining EOD duration. On days 1, 12 and 24, we digitized selected EODs that had been recorded on instrumentation tape during behavioural observations at a sampling rate of $250 \mathrm{kHz}$ (computerised A/D system, see above). Because of the reduced resolution we averaged eight EODs per fish and recording session.

IDI histograms were calculated using a geometrical progression of bin width with interval duration, as introduced by Graff (1989) and also used by Werneyer and Kramer (2002). In the present study a bin is referred to by its centre.

\section{Results}

The fish spawned on days 12 and 24 . The second spawning occurred during daylight, therefore, video images were of better quality than in night recordings. Since we also obtained fertilised eggs, we chose the second spawning event for a detailed analysis of overt behaviour and electrical activity. We also made observations in the period preceding reproduction.
Overt behaviour and IDI patterns during the day (mesh partition present)

During the day, the male would hover inside his shelter. The female hovered only for short periods of time but sometimes rested motionlessly. She often swam around slowly, most of the time foraging or probing the recording electrodes. Usually she remained close to her shelter and approached the mesh partition only for short periods of time while foraging. Within the IDI patterns shown in Fig. 2, the female switched repeatedly between moderate swimming activity, hovering and motionless resting, and the changes in overt behaviour were accompanied by distinct changes in IDI pattern. When swimming, IDIs ranged from $14.6-318.5 \mathrm{~ms}$, but $95 \%$ of the IDIs were from $20-100 \mathrm{~ms}$. On one particular occasion (not shown), the IDI briefly dropped to $14.6 \mathrm{~ms}$ when the female retreated in a flash from the open space in front of her shelter, as if alarmed by a disturbance. While resting motionlessly, the female generated an IDI pattern ranging from $22.6-2,095.7 \mathrm{~ms}$ (95\% of IDIs were from $50-250 \mathrm{~ms}$ ), characterised by abrupt changes. The hovering male generated a similar pattern, with IDIs ranging from $27.1-26,575.1 \mathrm{~ms}$, but $95 \%$ of IDIs were from $50-300 \mathrm{~ms}$. 
Fig. 2. Simultaneous interdischarge interval (IDI) patterns in a male and a female bulldog recorded during the day (fish were separated by a mesh partition). The male hovered inside his shelter, and the female switched between motionless resting, hovering and moderate swimming. The ordinate was cut off at $300 \mathrm{~ms}$. IDIs above $300 \mathrm{~ms}$, therefore, are not shown

Fig. 3. Simultaneous IDI patterns in a male and a female bulldog (separated by a mesh partition), recorded at night. The fish swam around or foraged but did not show any obvious interactions even though they passed alongside each other at close distance at $15 \mathrm{~s}$
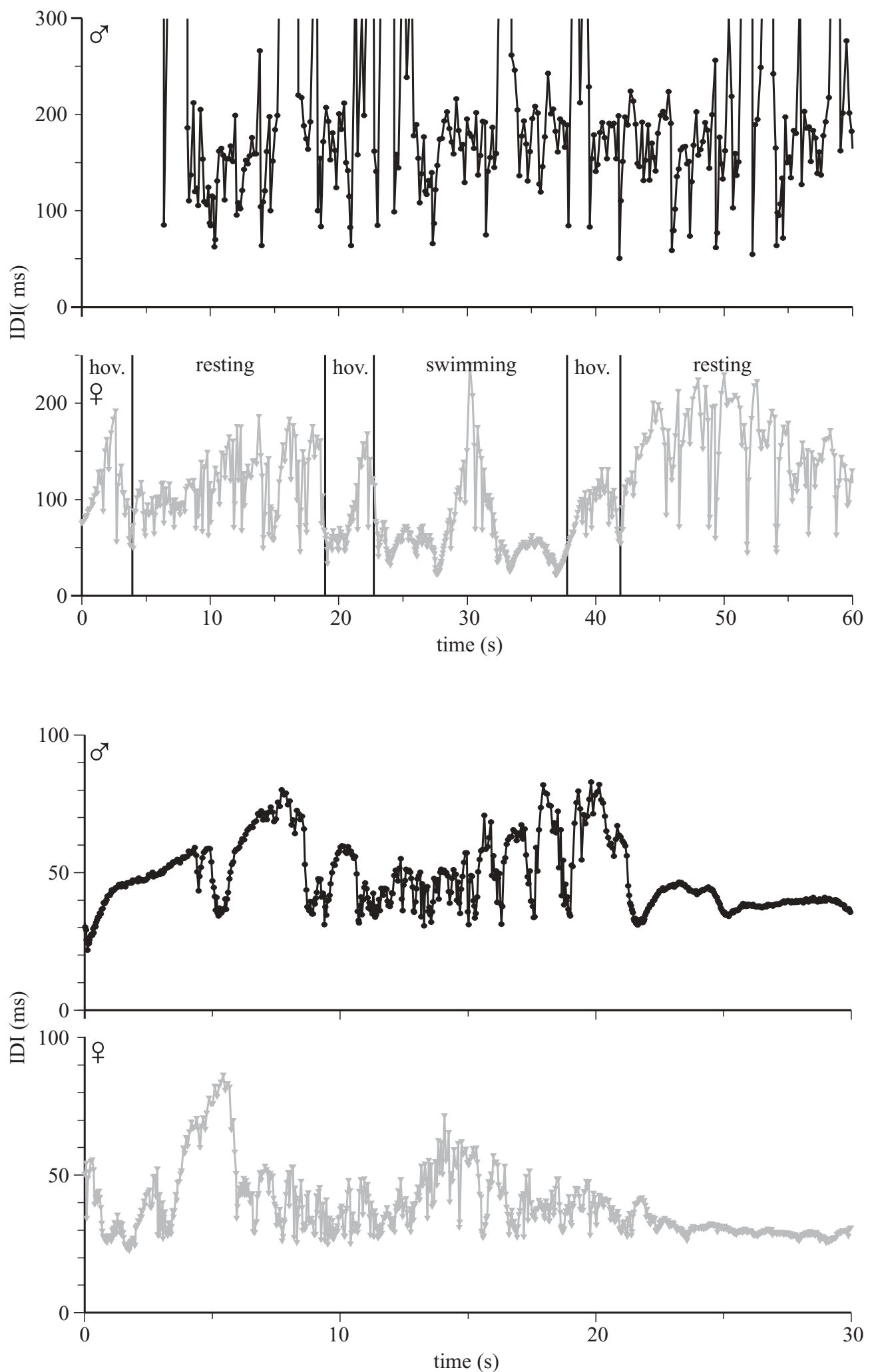

Nocturnal activity without interaction (mesh partition present)

Figure 3 shows IDI patterns, recorded 2 min after dark, when both fish were swimming around or foraging.
Although fish often moved within detection range of each other's EODs (less than $0.5 \mathrm{~m}$, Squire and Moller 1982), they showed no overt interaction. Compared to the resting IDIs, here the IDIs were restricted to a narrow range: 21.8 $85.5 \mathrm{~ms}$ in the male and $22.6-95.5 \mathrm{~ms}$ in the female. 
Agonistic interaction at the mesh partition

Immediately after dark the fish obviously interacted when moving along the mesh partition, keeping within close distance of each other. Their movements seemed highly synchronised. Interactions resembled agonistic behavioural patterns observed in paired males (Werneyer and Kramer 2002). Several times fish performed parallel swimming, they tried to attack each other through the mesh, and on one occasion they performed an antiparallel display. The mesh partition obviously prevented physical interactions, and the fish were able to perform parallel swimming only for the short length of the mesh partition, not along the long dimension of the aquarium. Figure 4 shows a sequence where the fish alternated between apparently independent activities and obvious interactions. The onset of interaction was accompanied by a distinct change in IDI pattern in both fish: a regular IDI pattern, gradually changing within a range from about 20-100 ms [male: (mean \pm SD) $42.3 \pm 10.3 \mathrm{~ms}, n=689$; female: $31.5 \pm 7.1 \mathrm{~ms}, n=923$ ], was replaced by a pattern of switching abruptly between very long IDIs (especially in the male, see Fig. 4) and series of extremely short IDIs (termed $\mathrm{HD}=$ high discharge rate, sensu Kramer 1996). Both fish generated IDIs as short as 10-15 ms during HD displays.

Interaction when the separating mesh partition was removed

This encounter consisted of four stages:
1. The first 2 min: After removal of the mesh partition just before dark, the female swam to the male's shelter as soon as the lights were switched off. Almost immediately the fish started interacting agonistically, performing parallel swimming and HD displays (Fig. 5). However, overt hostilities stopped quickly.

2. The next $5 \mathrm{~min}$ : Although the male in particular continued displaying HDs as well as low-rate inter-HD activity, he showed no aggression towards the female even though the female stayed inside the male's territory most of the time, and the fish passed each other at close distance several times. For example, in one instance when the male approached the female as she foraged within his territory, the female stopped foraging and swam towards the male which turned away and left the site. HD displays in the male were not correlated with a specific overt behaviour or close contact with the female. The female, too, generated HDs occasionally, apparently when the male came too close, whereupon the male turned away. The male's frequent HD displays, in spite of his strongly reduced aggression towards the female, closely resembled his behaviour during spawning, which is described in detail below.

3. The next $7 \mathrm{~min}$ : The male obviously became more aggressive. At first he turned towards the quickly escaping female only occasionally, but finally he chased the female persistently. In contrast to the preceding stages, the female was now clearly subordinate.

4. The next $90 \mathrm{~min}$ : Finally both fish almost totally stopped discharging, and interaction seemed to be greatly reduced although the fish still swam around a lot.

Fig. 4. Simultaneous IDI patterns in a male and a female bulldog, separated by a mesh partition, recorded at night. Between time points $A$ and $B$, and also to the right of time point $C$, the fish interacted with highly synchronised movements and in close contact with each other at the mesh partition. The inset shows a period of parallel swimming (horizontal black bar) at better resolution. Note the series of very short IDIs (HD) displayed by both fish. Between periods of interaction the fish separated for foraging (female), or swam about at the mesh partition (male). Note the distinct change in IDI pattern in both fish when interacting

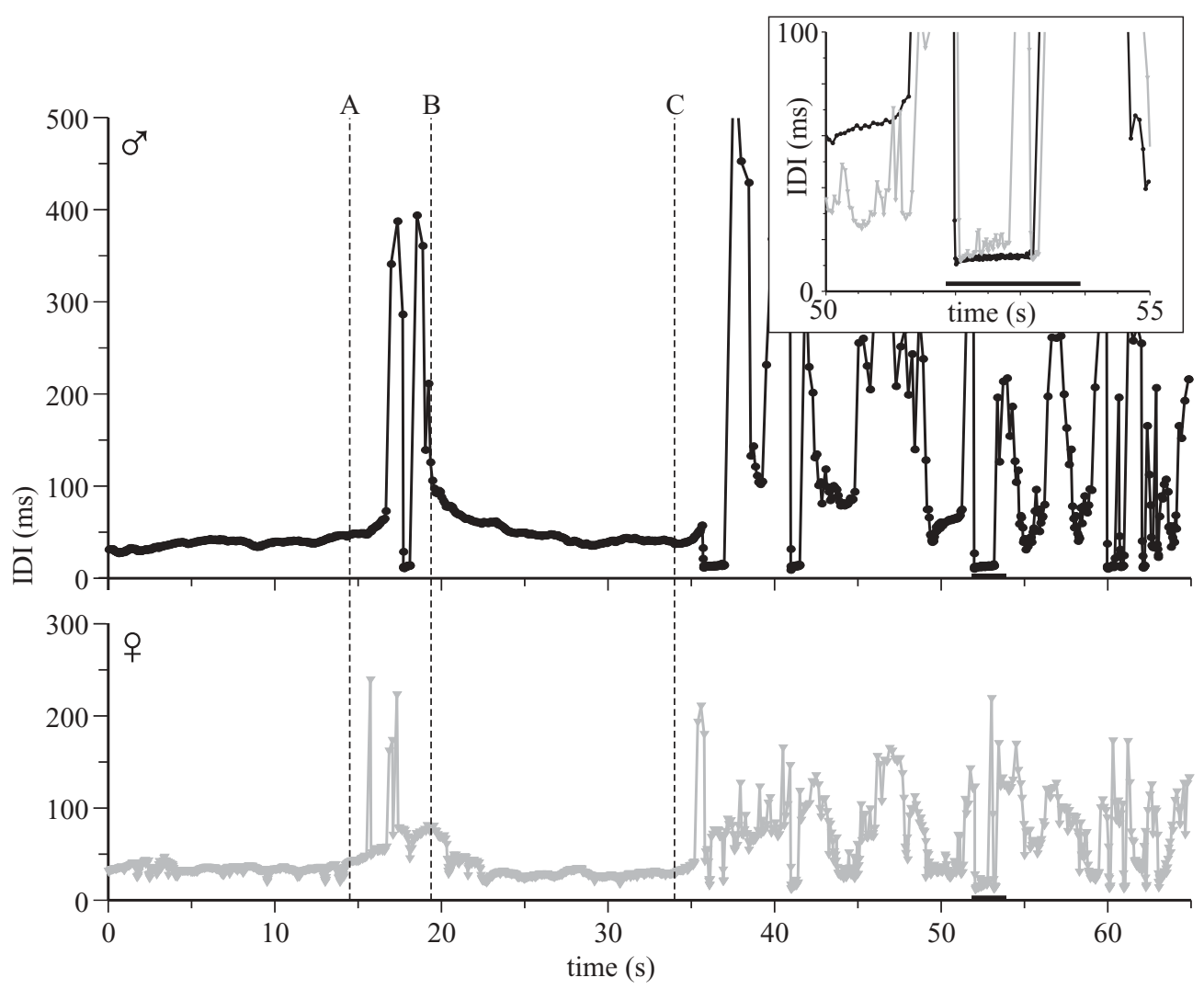


Fig. 5. Simultaneous IDI patterns (above) and overt behaviour (below) in a male (black) and a female (grey) bulldog, recorded at night (mesh partition removed). $A$ The fish passed each other without obvious interaction. $B$ They started parallel swimming, which was terminated by the female attacking the male $(C)$. Note the change in IDI pattern in both fish when interaction started and also the HD displays in both fish

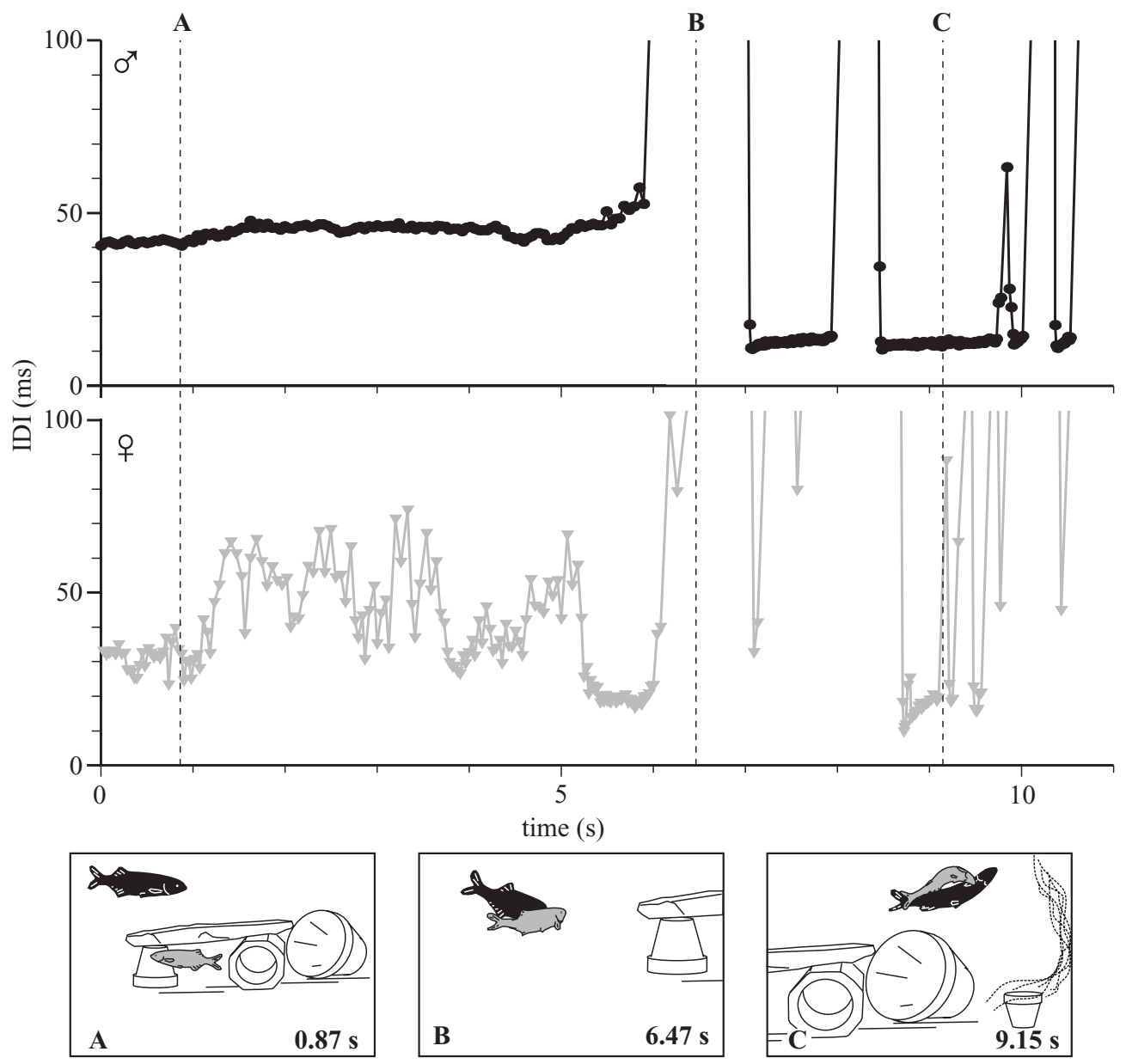

However, the female still had to flee when too close to the male (Fig. 6).

First spawning

Upon removal of the mesh partition shortly before dark, the female swam over to the male's compartment. When the lights went off automatically, the fish started spawning. In general, overt behaviour and electrical activity resembled what was observed during the second spawning (which is described in detail below) but sometimes seemed less distinct and less synchronised. Even while spawning carried on, the female seemed to start eating the eggs, as indicated by distinct foraging behaviour close to the spawning site (also no eggs were present on the next morning). The male showed only little foraging behaviour during this period. Spawning lasted for about $45 \mathrm{~min}$, but the number of released eggs and the frequency of spawning bouts soon decreased. When spawning was over, fish soon reduced their discharge activity and went almost "silent", and overt interaction was also greatly reduced. After about $70 \mathrm{~min}$ we manoeuvred the female back into her own compartment and put the mesh partition back in place. On day 20 we introduced Java moss (Vesicularia dubyana, regularly used for nest building in captive $P$. adspersus, see Bratton and
Kramer 1989) into the male's compartment but the male did not use it for nest building.

Second spawning

Figure 7 shows the male's compartment with the shelter area where the fish spawned a second time. On finding some eggs near the mesh partition in the early afternoon, we removed the partition. The female swam over to the male immediately, and after about 2 min, the first spawning bout occurred. The fish spawned 27 times within 20 min after removal of the mesh partition, but spawning frequency was highest within the first few minutes (up to three spawning bouts per minute). A spawning bout lasted only a few seconds, then the fish separated again. However, the female remained within the male's territory almost all the time, and the male showed very little aggression. The fish always spawned close to the male's shelter and never at the female's shelter in spite of the similarity of structures present (flat stones, porous pots, etc.). The female's shelter was separated from the male's shelter by some open space where the mesh partition had been. Again the female seemed to eat the eggs; therefore, after about $20 \mathrm{~min}$, when spawning frequency was declining, we removed both fish from the aquarium. Four days later the larvae hatched. 
Fig. 6. Simultaneous IDI patterns (above) and overt behaviour (below) in a male (black) and a female (grey) bulldog, recorded at night (mesh partition removed). This sequence was recorded about 18 min after the sequence shown in Fig. 5. The female was clearly subordinate to the male. Both fish had almost stopped discharging. $A$ The male overtook the more slowly swimming female at close distance but without attacking. The male turned around and at $11 \mathrm{~s}$ the fish bumped into each other head-on, evoking a single EOD in the female (arrow, lower graph). The fish quickly turned away from each other $(B)$ but almost immediately the male chased the escaping female $(C)$

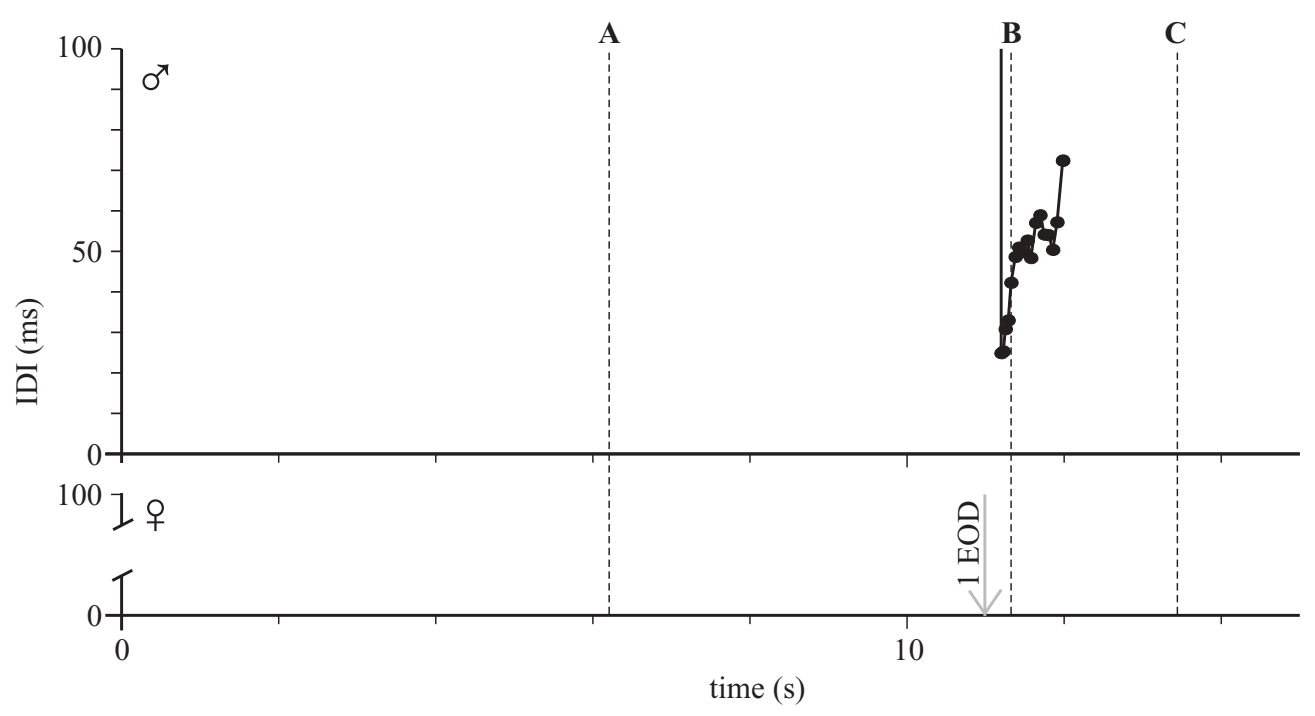

Fig. 7. The male's territory where the fish spawned, usually close to the porous pot (1) below the flat stone (2), as indicated by arrows. On the right, Java moss (Vesicularia dubyana) in front of a flowerpot (3); the Java moss was not used for spawning. The vertical rods are electrodes fixed to the aquarium walls with suction cups (video image recorded on day 24 in the early afternoon)
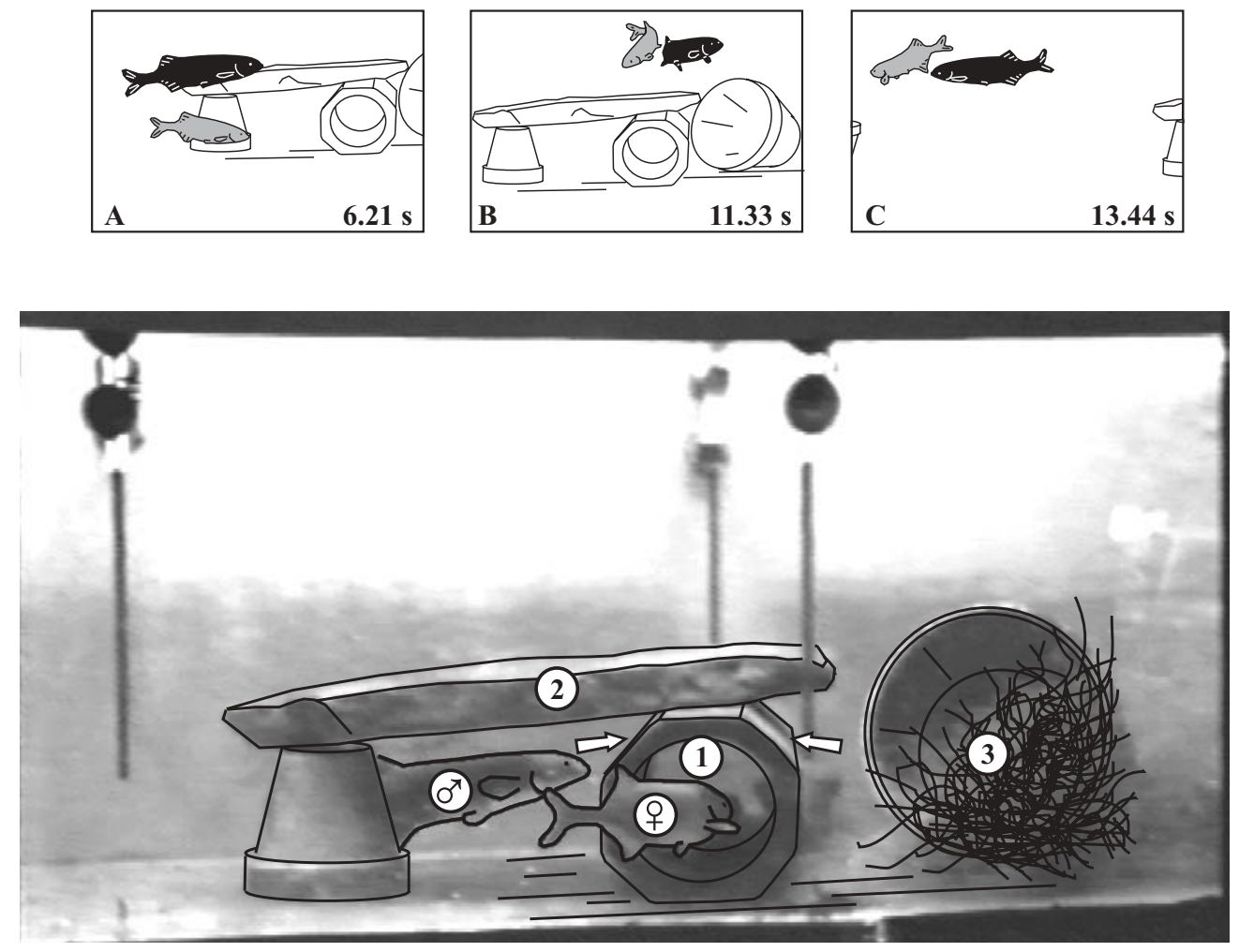

The male showed a conspicuous pattern of switching between long IDIs and HD displays almost without transition. Within a period of $3 \mathrm{~min}$, including the section presented in Fig. 8, the male generated $20 \mathrm{HD}$ displays that were highly stereotyped: a very regular IDI sequence started almost without transition from low-rate inter-HD activity. IDI duration (total range, 8.4-14.7 ms) slightly increased during an HD display towards an abrupt end (see Fig. 8b). The number of IDIs varied from 24-174. The female's HD displays sometimes started less abruptly than the male's, or were interrupted by longer IDIs (see Fig. 8b). The shortest IDI for a female HD display (10.6-14.9 ms) usually occurred towards the middle. Some of the female's
HD displays were very short, consisting of only a few short IDIs. However, the female's longest HD display included a continuous series of 76 IDIs of 10.6-14.9 ms, which is almost half of the male's longest HD displays.

In the male, HD displays were not correlated with a specific interaction or a specific overt behaviour. For example, the male started HD displays when moving towards or away from the female, or while hovering temporarily. The female apparently generated HD displays whenever the male came too close. Sometimes, but not always, the female retreated from the male while generating an HD.

We analysed the first seven spawning bouts in detail. For the first spawning bout it was not possible to determine 
Fig. 8a,b. a Simultaneous IDI patterns in a male and a female bulldog, recorded during daylight. The fish spawned three times (at 14, 45 and $56 \mathrm{~s}$, arrows). Note the abrupt changes between long IDIs and HD displays, generated especially by the male. b HD displays for female and male at better resolution. Note sequences of regular IDIs in both fish during HD
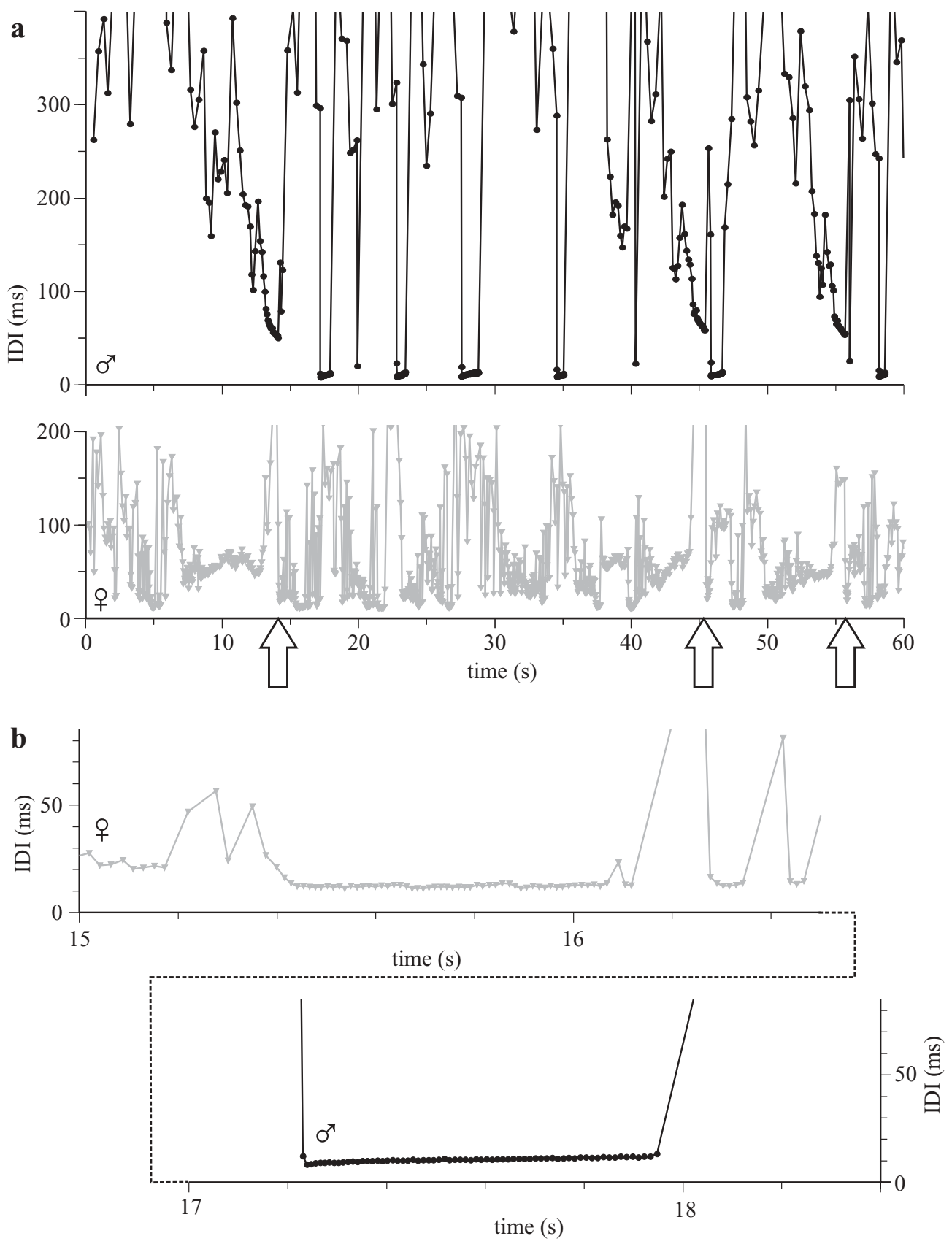

whether (and if so, how many) eggs were released, because fish spawned in the shadow of a flat stone. The number of eggs released in the following six spawning bouts varied from about 25-60 eggs per bout.

Overt behaviour and IDI pattern during spawning bouts were stereotyped (Fig. 9): the female chose either the right or the left cleft between the porous pot and the flat stone (other places were chosen less often, and the fish did not use Java moss for spawning). The female seemed to probe the cleft with her snout, as if foraging. The male approached the female, and both fish turned round into a position parallel to each other and the pot, remaining in this position for about 1.5-2 s. The female was between the male and the porous pot (see Fig. 9). It was not possible to determine exactly when the eggs were released by the female. Shortly thereafter and with strong tail flips, the female left the spawning site abruptly, scattering the eggs and displacing the male laterally. The male swam away about $0.5-1 \mathrm{~s}$ later.

While parallel to the female, the male generated a highly stereotyped series of decreasing IDIs, starting with an IDI of about $200 \mathrm{~ms}$ and decreasing to a series of regular IDIs of about $60 \mathrm{~ms}$ (Fig. 10a). The series was terminated abruptly by a long IDI ranging from 131-395 ms. The female generated regular IDIs of about $54 \mathrm{~ms}$, approximately when moving into a parallel position relative to the porous pot (Fig. 10b). This series was terminated by a series of long IDIs (longest IDI 160.4-813.4 ms) that was about simultaneous with the male's series of regular IDIs. The female's 
Fig. 9. Simultaneous IDI patterns (above) and overt behaviour (below) in a male (black) and a female (grey) bulldog during a spawning bout. The female probed the cleft between porous pot and flat stone with her snout as if foraging $(A)$. The male approached from behind $(B)$ and both fish turned parallel to the porous pot where they remained for about $2 \mathrm{~s}(C)$. Within this period of time the eggs were released. The female left the site abruptly $(D)$. The male left about $1 \mathrm{~s}$ later $(E)$ and the fish separated temporarily $(F)$. Eggs were dispersed by the vehement movements of the abruptly leaving female; they are indicated by black dots in $E$ below. While alongside the female, the male generated a series of decreasing IDIs, terminated abruptly at $D$. Note a series of constant IDIs in the female $(B-C)$, followed by longer IDIs of variable duration (from about $C-D$ ), and a sharp decrease in IDI duration (at $D$ )
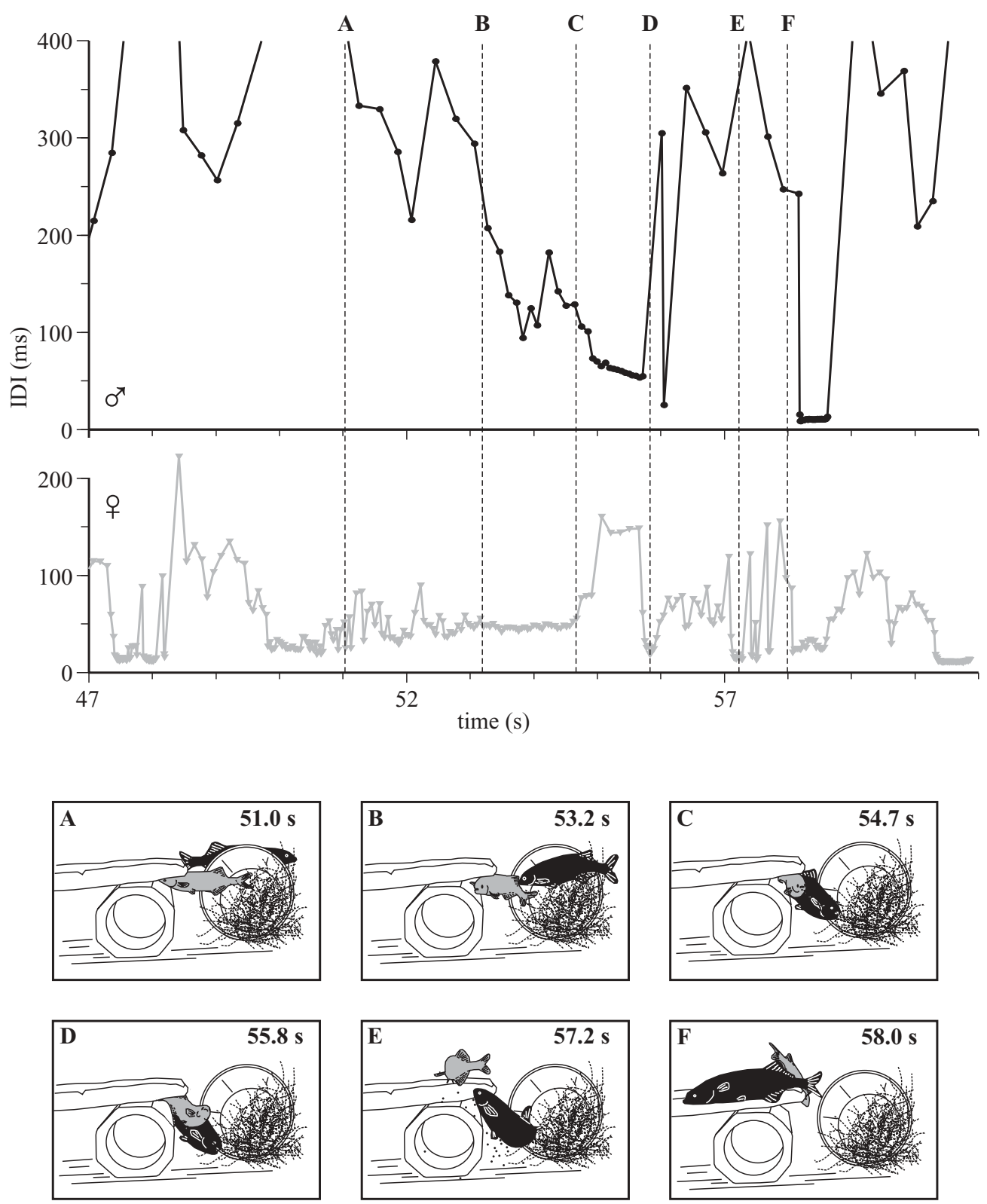

sudden escape was accompanied by a sharp decrease in female IDI duration (shortest IDI 17.9-20.8 ms, which is well above the shortest IDIs observed during HD displays). Three IDI sequences from the first spawning were not always as distinct and precise as those from the second spawning but clearly showed the same trends.

During reproductive behaviour, IDI histograms showed a distinct mode at $11.6 \mathrm{~ms}$ in both fish (Fig. 11). In the male, this mode was prominent, whereas the female showed at least one further distinct mode at $48.3 \mathrm{~ms}$. IDIs as short as $11.6 \mathrm{~ms}$ were only generated when the fish interacted; the modes of IDI histograms for nocturnal activities (when the fish swam around or foraged, but did not interact) were $30.0 \mathrm{~ms}$ in the female and $39.9 \mathrm{~ms}$ in the male. As mentioned above, the female also left her shelter for prolonged periods of time during the day. The female's IDI histogram mode for diurnal activities was $33.0 \mathrm{~ms}$.

\section{Waveform of EOD}

As shown earlier, the EOD was biphasic in both sexes. A head-positive first phase was followed by a head-negative second phase and a very weak postpotential. This basic type of waveform remained stable throughout the observation period, and EOD duration in the female showed very little variation $(0.34-0.37 \mathrm{~ms}$; normalised to a water temperature of $25^{\circ} \mathrm{C}$ using a $\mathrm{Q}_{10}$ of 1.5 , Kramer and Westby 1985). EOD duration in the male varied considerably among recording sessions on different days $(0.52-0.92 \mathrm{~ms}$, Fig. 12a). Female EODs recorded on the same day were almost identical. This holds also for male EODs on days when his EOD duration was relatively short. When, however, his EOD was of longer duration, a slight variation occurred, as shown in Fig. 12b (upper male recording). Male EOD duration was short at the first spawning, but long at the second spawning. The 
Fig. 10a,b. a Seven superimposed IDI patterns from the second spawning and three from the first spawning in a male bulldog when parallel to a female during spawning bouts, aligned so that the last EOD in a series of decreasing IDIs (as shown in Fig. 9) occurred at $10 \mathrm{~s}$. Note the stereotyped IDI patterns from $8.5 s$ to $10 s$. b Seven superimposed IDI patterns from the second spawning and three from the first spawning generated by the female bulldog during spawning bouts showing the simultaneous activity relative to a. We used the period from 7.3 to $8.8 \mathrm{~s}$ (between arrows), during which IDIs remained relatively stable in all ten IDI patterns, to calculate a mean $( \pm$ SD) IDI $(53.7 \pm 5.1 \mathrm{~ms} ; n=10)$
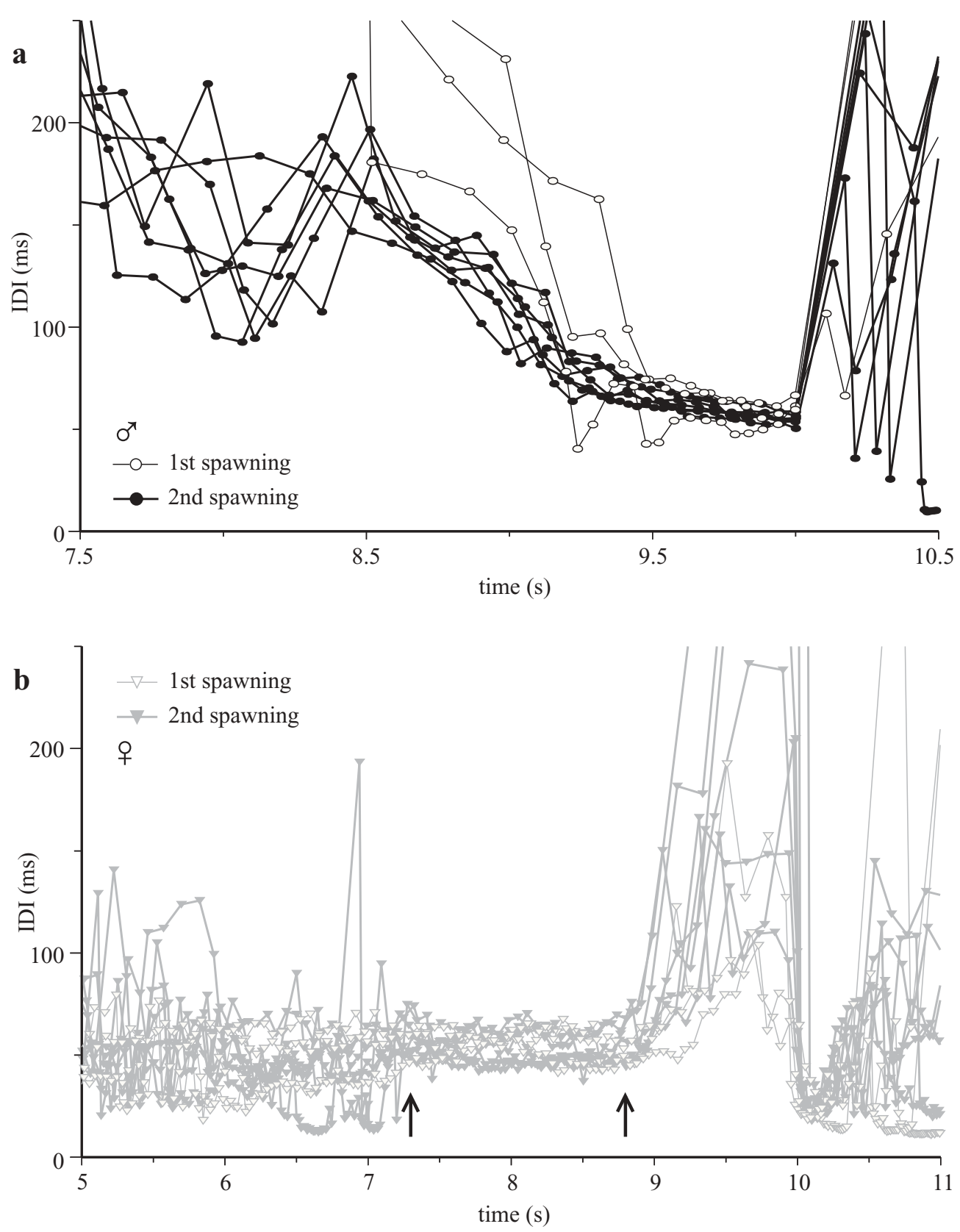

changes in male EOD duration occurred in both the positive and negative phases simultaneously.

\section{Discussion}

\section{Agonistic behaviour}

Werneyer and Kramer (2002) described agonistic behavioural patterns (such as attack, parallel swimming, antiparallel display, fleeing/chasing or retreating) observed in pairs of male bulldogs during confrontation tests. Fighting was accompanied by HD displays that alternated rapidly with periods of very long IDIs almost without transition. Regarding agonistic overt behaviour and concomitant IDI patterns in a non-reproductive context, there was very little difference between male-male pairs studied by Werneyer and Kramer (2002) and the heterosexual pair of this study.

\section{Reproductive behaviour and ecology}

Eggs were found in our aquaria holding bulldogs from the Sabie River during periods of reduced maintenance, when fish were left on their own for prolonged periods of time except for daily feeding (I. Kaunzinger, personal observation). Skelton (2001) notes that bulldogs breed in the rainy season, and he also reports migrations in bulldogs, but it is not clear whether they are linked to reproduction, and whether this observation holds for all bulldog populations from southern Africa (suggested to represent more than a 
Fig. 11a,b. IDI histograms for a female (a) and a male (b) bulldog fish. Note prevalence of short IDIs and wide range in spawning fish, which is in contrast to other histograms shown for fish that did not interact. IDI sequences during spawning and diurnal activities were recorded at $22^{\circ} \mathrm{C}$ IDI sequences during nocturnal activities at $20^{\circ} \mathrm{C}$. Sections of the data are shown in Figs. 2, 3 and 8 as sequential plots of IDI over time
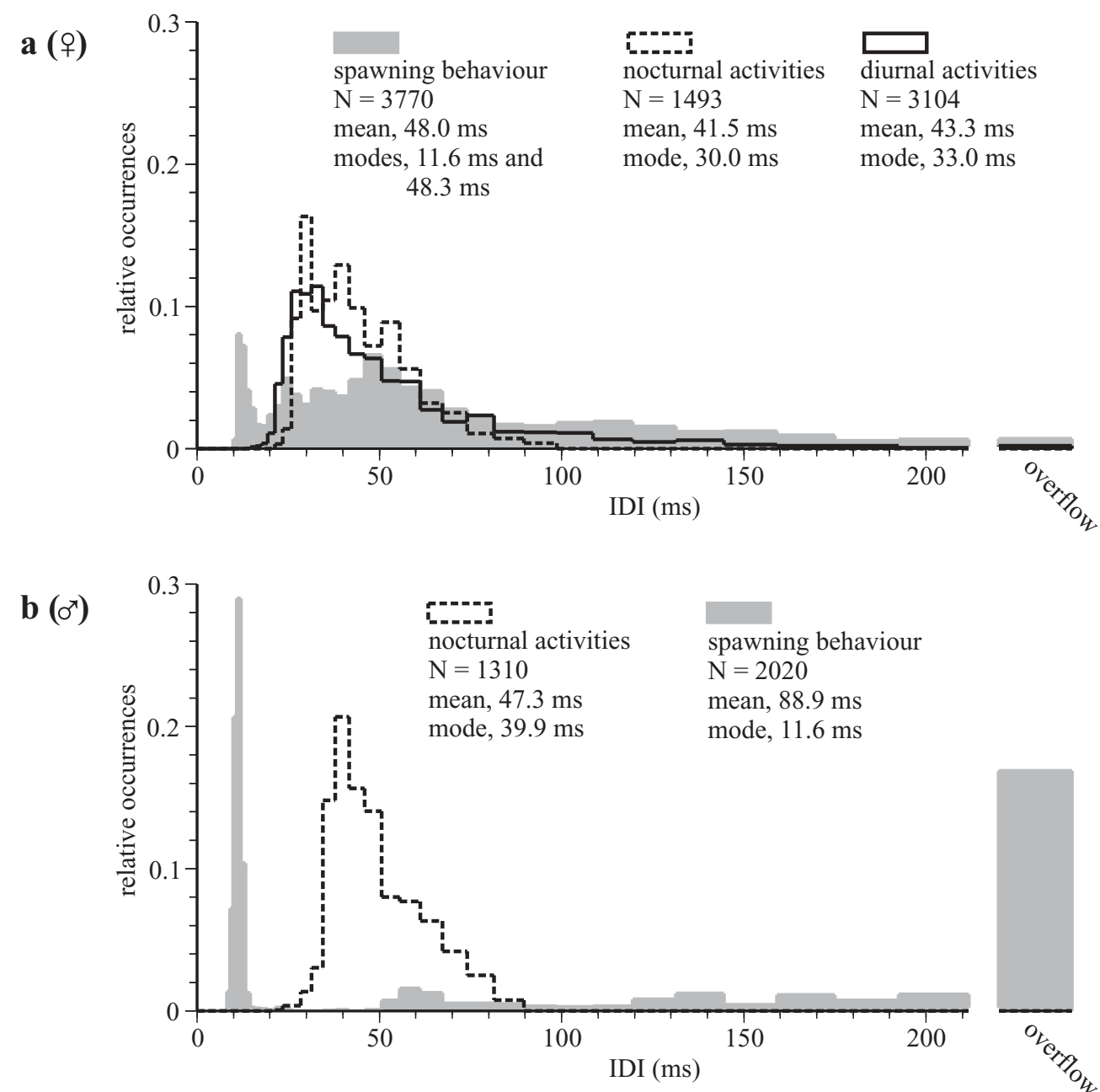

single species; Kramer et al. 1998, in preparation). Other observations (Birkholz 1969; Kramer 1990b) also indicate that, at least in certain mormyrid species, reproduction may occur in aquaria even when no effort is made to control water conductivity, $\mathrm{pH}$, water level, etc. (but see Kirschbaum 1995).

Detailed information about reproductive behaviour in captivity exists only for $P$. adspersus (Kirschbaum 1987; Bratton and Kramer 1989). There are fundamental differences between the reproductive behaviour of $P$. adspersus and M. macrolepidotus. The male P. adspersus builds a nest and guards the eggs and larvae. In M. macrolepidotus, there were no signs of any parental care whatsoever. The male did not build a nest, and the eggs were scattered by the female's tail flips when leaving the spawning site after each spawning bout. The male did not collect and gather the eggs in its nest as a P. adspersus male would do. The female bulldog even appeared to eat the eggs. Egg-eating in captivity has been also observed in Mormyrus rume proboscirostris (Kirschbaum 1995), and is a common phenomenon observed in captivity, but may also occur in nature (FitzGerald 1992). In order to protect the fry, we removed the parent fish from the aquarium when spawning activity began to wane. Thus it is not quite clear whether the male would have guarded the eggs after spawning.
For several hours preceding spawning, P. adspersus exhibited a complex courtship behaviour (Bratton and Kramer 1989). The P. adspersus male's high level of aggression towards the female slowly decreased during this period. The P. adspersus female retreated frequently from the male's territory during courtship and between spawning bouts. In M. macrolepidotus we did not observe any extended or elaborate courtship behaviour; on removal of the mesh partition, the fish started spawning within minutes. Almost all of the time the female remained within the male's territory, and the male showed very little aggression. The female seemed to select the exact spawning site, waiting for the male to arrive. Also the female left first after spawning. In P. adspersus, the female appeared first at the specific spawning site, too, but the male left first. However, in both species spawning occurred in the male's territory, and both species spawned in bouts.

Electrical activity during reproductive behaviour

Testosterone administration increases the EOD duration of several mormyrid species (e.g. Bass and Hopkins 1985; Landsman and Moller 1988). Therefore, it seems reasonable to assume that changes in EOD duration in the male are 
Fig. 12a,b. a EOD duration over time in a female (grey) and a male (black) bulldog fish (all values normalised to a water temperature of $25^{\circ} \mathrm{C}$ using a $\mathrm{Q}_{10}$ of 1.5), starting from the day after the fish were put together into the same tank. Fish spawned twice (arrows). The female's EOD waveform remained stable throughout, whereas the male's EOD duration varied considerably. b For each waveform, four single-sweep samples were superimposed. Note the similarity of superimposed EODs from the same recording session in both the female and the male, in contrast to the variation observed in the male on different days

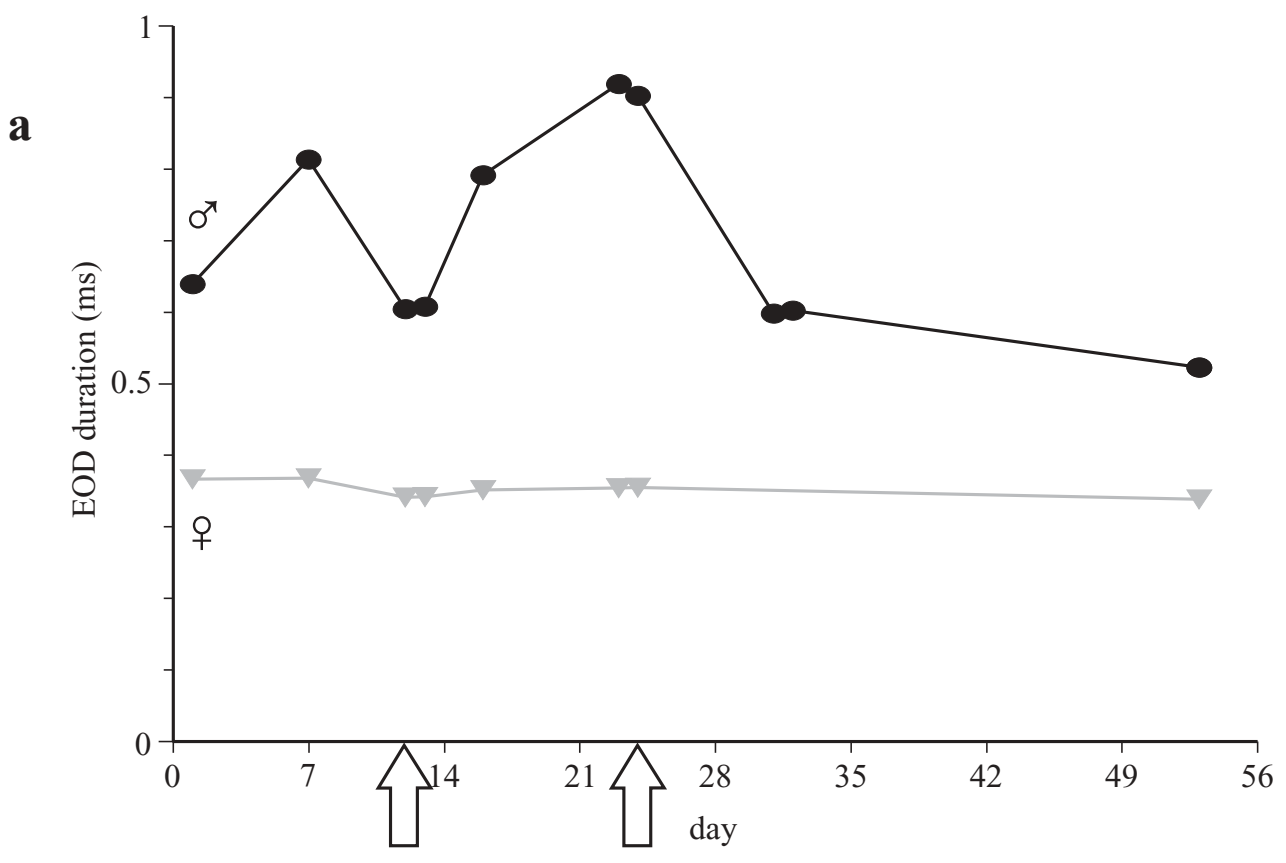

b

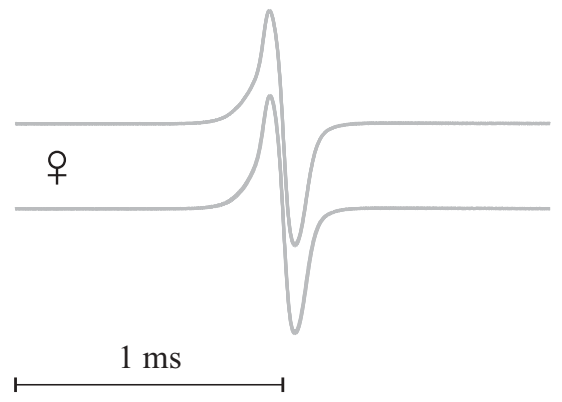

correlated with changes in hormonal state during the reproductive cycle. An increase in EOD duration during reproduction has already been observed in our laboratory in the male bulldog from South Africa (I. Kaunzinger, in Kramer in preparation). According to a field study, male bulldogs from the Upper Zambezi (Namibia) increased their EOD duration up to 11 times the female average on becoming sexually mature (Kramer 1997). In the present study, it was the removal of the mesh partition by the experimenter that allowed the male to be suddenly visited by a gravid female, which led to the onset of spawning; this may explain why the male had an EOD of short duration at the first spawning. Ultimately, an EOD of long duration might result from sexual selection for longer EODs in bulldog fish (Kramer 1997; Hanika and Kramer 2005 as also suggested for pulsetype gymnotiform fish (Hopkins et al. 1990; Curtis and Stoddard 2003).

During spawning bouts, female $P$. adspersus showed periods of very regular, ca. 100-ms IDIs (medium uniform rate, MUR, Bratton and Kramer 1989), exclusively generated during reproduction. A period of regular IDIs also occurred in the female M. macrolepidotus during spawning bouts, but similar IDI series also occurred during the day, in the absence of any overt interactions between the fish. The signal value of stereotyped IDI patterns during spawning bouts remains to be determined.

Our reproductive male's conspicuous IDI pattern of HD displays, rapidly alternating with low-rate inter-HD activity, closely resembled IDI patterns observed during agonistic interactions (the present study; and Werneyer and Kramer 2002 , showing data from the same male individual that was also used in the present study). Several authors have pointed out that HDs are not well suited to improving active electrolocation by increasing electrosensory input (Kramer and Bauer 1976; Moller 1995), and the present study supports this view (for example, the sharp contrast between the very low-rate inter-HD and HD activities that switched back and forth for prolonged periods of time). To assume that HD results simply from increased overt motor-activity stimulation is another unsatisfactory explanation, since overt motor activity was of moderate or even low intensity during HD displays on several occasions. Therefore, a signal 
function of the HD display in the context of both reproductive and agonistic behaviour is much more likely. By generating HDs of long duration, a male bulldog would demonstrate power and strength, to deter rivals or to attract females. Both functions were expressed when the mesh partition was removed for the first time: at first the fish interacted agonistically including HD displays - probably because the male defended its territory. However, having identified the intruder as a potentially gravid female, the male stopped aggression and started HD displays as courtship signals. Probably because the female was not willing or able to spawn she finally was chased away by the male.

In both species, $P$. adspersus and M. macrolepidotus, HD displays regularly occurred during agonistic interactions as well as during reproductive behaviour (Bratton and Kramer 1989; Werneyer and Kramer 2002; the present study). However, in $P$. adspersus, HD displays occurred during courtship and spawning when the male attacked the female, whereas in $M$. macrolepidotus, especially in the male, HD displays during reproduction were obviously not correlated with overt aggression.

We had already found strong evidence for a communication function of HD displays as contrasting with the low rate inter-HD activity in an agonistic context (Werneyer and Kramer 2002). The present study adds another context reproduction - where this pattern again appears to be a communication signal.

Acknowledgements We wish to thank Dr. F.H. van der Bank (Rand Afrikaans University [now the University of Johannesburg, Kingsway Campus], RSA) and Dr. J. Engelbrecht (Mpumalanga Parks Board, RSA) for sampling and exporting our test fish from the field. The observations and experiments comply with the current laws of Germany. This work was supported by the Deutsche Forschungsgemeinschaft (DFG), grants Kr446/10-4 and Kr446/10-5.

\section{References}

Bass AH, Hopkins CD (1985) Hormonal control of sex differences in the electric organ discharge (EOD) of mormyrid fishes. J Comp Physiol A 156:587-604

Bauer R (1972) High electrical discharge frequency during aggressive behaviour in a mormyrid fish, Gnathonemus petersii. Experientia 28:669-670

Bauer R (1973) Electric organ discharge activity of resting and stimulated Gnathonemus petersii (Mormyridae). Behaviour 50:306-323

Bell CC, Myers JP, Russell CJ (1974) Electric organ discharge patterns during dominance related behavioral displays in Gnathonemus petersii (Mormyridae). J Comp Physiol 92:201-228

Birkholz J (1969) Zufällige Nachzucht bei Petrocephalus bovei. Aquarium 3:201-203

Bratton BO, Kramer B (1989) Patterns of the electric organ discharge during courtship and spawning in the mormyrid fish, Pollimyrus isidori. Behav Ecol Sociobiol 24:349-368

Curtis CC, Stoddard PK (2003) Mate preference in female electric fish, Brachyhypopomus pinnicaudatus. Anim Behav 66:329-336

FitzGerald GJ (1992) Filial cannibalism in fishes: why do parents eat their offspring? Trends Ecol Evol 7:7-10

Graff B (1989) Firing activity of the weakly electric fish Marcusenius macrolepidotus (Mormyridae, Teleostei): logarithmic repartition of inter-pulse intervals and sequential inequality testing. Behaviour 109:258-284

Hanika S, Kramer B (2005) Intra-male variability of its communication signal in the weakly electric fish, Marcusenius macrolepidotus, and its possible functions. Behaviour (in press)

Hopkins CD (1999) Design features for electric communication. J Exp Biol 202:1217-1228

Hopkins CD, Comfort NC, Bastian J, Bass AH (1990) Functional analysis of sexual dimorphism in an electric fish, Hypopomus pinnicaudatus, order Gymnotiformes. Brain Behav Evol 35:350-367

Kirschbaum F (1987) Reproduction and development of the weakly electric fish, Pollimyrus isidori (Mormyridae, Teleostei) in captivity. Environ Biol Fish 20:11-31

Kirschbaum F (1995) Reproduction and development in mormyriform and gymnotiform fishes. In: Moller P (ed) Electric fishes. History and behavior. Chapman \& Hall, London, pp 267-302

Kramer B (1974) Electric organ discharge interaction during interspecific agonistic behaviour in freely swimming mormyrid fish. A method to evaluate two (or more) simultaneous time series of events with a digital analyser. J Comp Physiol 93:203-235

Kramer B (1976) Flight-associated discharge pattern in a weakly electric fish, Gnathonemus petersii (Mormyridae, Teleostei). Behaviour 59:88-95

Kramer B (1979) Electric and motor responses of the weakly electric fish, Gnathonemus petersii (Mormyridae), to play-back of social signals. Behav Ecol Sociobiol 6:67-69

Kramer B (1990a) Electrocommunication in teleost fishes: behavior and experiments. Springer, Berlin Heidelberg New York

Kramer B (1990b) Sexual signals in electric fish. Trends Ecol Evol 5:247-250

Kramer B (1996) Electroreception and communication in fishes. Gustav Fischer, Stuttgart

Kramer B (1997) A field study of African elephantfish (Mormyridae, Teleostei): electric organ discharges in Marcusenius macrolepidotus (Peters, 1852) and Petrocephalus catostoma (Günther, 1866) as related to sex. J Afr Zool 111:313-341

Kramer B, Bauer R (1976) Agonistic behaviour and electric signalling in a mormyrid fish, Gnathonemus petersii. Behav Ecol Sociobiol 1:45-61

Kramer B, Westby GWM (1985) No sex difference in the waveform of the pulse type electric fish, Gnathonemus petersii (Mormyridae). Experientia 41:1530-1531

Kramer B, van der Bank FH, Skelton PH (1998) Two new species of snoutfish (Mormyridae) from South Africa: evidence from electric organ discharges. In: African fishes and fisheries: diversity and utilisation (abstract). Paradi conference, Grahamstown, South Africa, p 50

Landsman RE, Moller P (1988) Testosterone changes the electric organ discharge and external morphology of the mormyrid fish Gnathonemus petersii Mormyriformes. Experientia 44:900-903

Lissmann HW (1958) On the function and evolution of electric organs in fish. J Exp Biol 35:156-191

Lissmann W (1961) Ecological studies on gymnotids. In: Chagas C, Paes de Carvalho A (eds) Bioelectrogenesis. Elsevier, Amsterdam, pp 215-226

Möhres FP (1957) Elektrische Entladungen im Dienste der Revierabgrenzung bei Fischen. Naturwissenschaften 44:431-432

Moller P (1995) Electric fishes. History and behavior. Chapman \& Hall, London

Scheffel A, Kramer B (1997) Electrocommunication and social behaviour in Marcusenius senegalensis (Mormyridae, Teleostei). Ethology 103:404-420

Skelton P (2001) A complete guide to the freshwater fishes of southern Africa, 2nd edn. Struik, Cape Town

Squire A, Moller P (1982) Effects of water conductivity on electrocommunication in the weak-electric fish Brienomyrus niger (Mormyriformes). Anim Behav 30:375-382

Werneyer M, Kramer B (2002) Intraspecific agonistic interactions in freely swimming mormyrid fish, Marcusenius macrolepidotus (South African form). J Ethol 20:107-121 DOI 10.1007/s10164-002-0062-y 